\title{
1 Investigation on Quantitative Structure-Activity Relationships of 2 1,3,4-Oxadiazole Derivatives as Potential Telomerase Inhibitors
}

3 Marco Tutone*1, Beatrice Pecoraro², and Anna Maria Almerico ${ }^{1}$

$4 \quad{ }^{1}$ Dipartimento di Scienze e Tecnologie Biologiche, Chimiche e Farmaceutiche (STEBICEF) Università degli

5 Studi di Palermo, via Archirafi 28, 90123-Palermo-Italy.

$6 \quad{ }^{2}$ Department of Clinical and Pharmaceutical Sciences, School of Life and Medical Sciences, University of

7 Hertfordshire, College Lane, Hatfield, Hertfordshire AL10 9AB

8 e-mail: marco.tutone@unipa.it

9 This research did not receive any specific grant from funding agencies in the public, commercial, or not-for-

10 profit sectors.

Abstract: A series of 1,3,4-oxadiazole derivatives with significant broad-spectrum anticancer activity against different cell lines, and demonstrated telomerase inhibition, was subjected to Quantitative Structure-Activity Relationships (QSAR) analysis. Validated models with high correlation coefficients were developed. The Multiple Linear Regression (MLR) models, by Ordinary Least Squares (OLS), showed good robustness and predictive capability, according to the Multi-Criteria Decision Making (MCDM = 0.8352), a technique that simultaneously enhances the performances of a certain number of criteria. The descriptors selected for the models, such as electrotopological state (E-state) descriptors, and extended topochemical atom (ETA) descriptors, showed the relevant chemical information contributing to the activity of these compounds. The results obtained in this study make sure about the identification of potential hits as prospective telomerase inhibitors.

21

22 Keywords: 1,3,4-oxadiazoles, Anticancer activity, Telomerase inhibitors, QSAR, 2D descriptors, MLR.

*Address correspondence to this author at the Department of Scienze e Tecnologie Biologiche Chimiche e Farmaceutiche. Università degli Studi 


\section{INTRODUCTION}

Telomerase, a reverse transcriptase, maintains telomere and chromosomes integrity of dividing cells, while it is inactivated in most somatic cells $(1,2)$. In tumor cells, telomerase is highly activated, and works in order to maintain the length of telomeres causing immortality, hence it could be considered as a potential marker to tumorigenesis (35). The great advantage of targeting this reverse transcriptase, with respect to other cancer targets, is due to its strict specificity for cancer cells. In fact, it is expressed in up to the $90 \%$ of cancers $(6,7)$. Human telomerase consists of two portions: a template-encoding RNA (TER), and a reverse transcriptase part (TERT) which also consists of an essential $\mathrm{N}$-terminal domain (TEN), a telomerase RNA binding domain (TRBD), a reverse transcriptase domain (RT), and a C-terminal domain $(8,9)$. In the past decades, several classes of inhibitors were identified: oligonucleotides targeting the telomerase RNA templates (10), compounds targeting telomeric DNA(11), nucleosidic transcriptase inhibitors (12) and G-quadruplex stabilizing compounds as telomerase inhibitors $(13,14)$. Among this range of compounds' classes, different substituted 1,3,4-oxadiazoles showed potent anti-tumor activities (15-18), and in particular telomerase inhibitory activity $(18,19)$. Moreover, oxazole, bioisoster of 1,3,4-oxadiazole ring, is the scaffold of telomestatin, which is a natural product isolated from Streptomyces anulatus, with potent telomerase inhibitory activity (20). The emphasis of recent efforts to develop new telomerase inhibitors has been focused on structure-based design $(18,19,21-23)$. Ligand-based design by means of Quantitative Structure Activity Relationships (QSAR), an important application of chemometrics, revealed in the last years to be useful to obtain information in the design of new molecules against a specific target (24-26). Nevertheless, QSAR modeling is affected by one severe problem: model validation. In fact, in the past many QSAR models have been published as predictive, although not all the validation checks have been done. Therefore, model validation has been subject of many debates in scientific and regulatory communities. To date, to consider a QSAR model as predictive, this latter should be associated to defined OECD principles (27). A QSAR model, for regulatory purposes, and for the identification of new chemical entities in all the field of chemistry, should be associated with the following information: (1) a defined endpoint; (2) an unambiguous algorithm; (3) a defined domain of applicability; (4) appropriate measures of goodness-of-fit, robustness and predictivity; (5) a mechanistic interpretation, if possible. Our interest in the chemistry of oxadiazoles (28), and the alive pharmaceutical interest in this outstanding scaffold (29), have placed our attention to the structures-activity relationships, with the aim of underline the features which could increase anti-tumor activity. Even though other attempts have been carried out $(18,19,21,23,30)$, no validated models have been built according to OECD principles for 1,3,4-oxadiazoles as telomerase inhibitors, making predictive power and mechanistic interpretation not reliable. In this paper, our main aim is to develop validated and predictive models for 1,3,4-oxadiazole derivatives as telomerase inhibitors, according to the OECD principles, exploiting the great amount of available biological data. The models developed are commented by means of the selected descriptors, and some interesting mechanistic interpretations could be stated. 


\section{2.1. Dataset}

62 A series of 24 N-benzylidene-2-((5-(pyridine-4-yl)-1,3,4-oxadiazol-2yl)thio)acetohydrazide derivatives as 63 telomerase inhibitors has been considered to carry out QSAR studies (30). The endpoint to build QSAR models is 64 determined by the $\mathrm{IC}_{50}$ values for telomerase inhibition, i.e., the concentration $(\mu \mathrm{M})$ of inhibitor that produces $50 \%$ 65 inhibition. These values were converted to $\mathrm{pIC}_{50}\left(-\log \mathrm{IC}_{50}\right)$ values. In Table 1 the structure of the 24 compounds are 66 reported together with their biological data related to telomerase inhibition. 


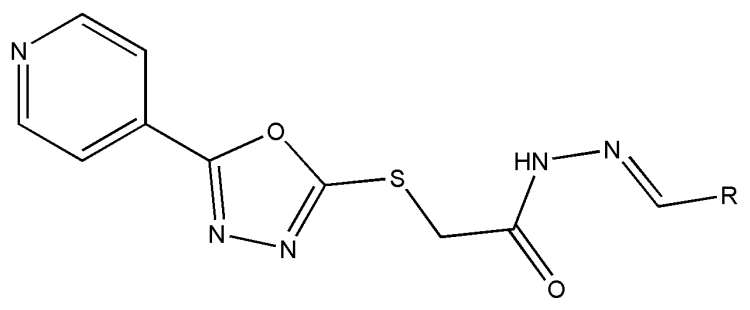

68

69 Table 1. Structures of 1,3,4-oxadiazole derivatives with activities

70

\begin{tabular}{|c|c|c|c|}
\hline $\begin{array}{l}\text { Comp } \\
\text { No. }\end{array}$ & $R$ & $\operatorname{Exp} \operatorname{pIC}_{50}{ }^{a}$ & QSAR set ${ }^{b}$ \\
\hline 1 & Ph- & 5.012 & Training \\
\hline 2 & $4-\mathrm{F}-\mathrm{C}_{6} \mathrm{H}_{4}-$ & 4.992 & Training \\
\hline 3 & $4-\mathrm{Cl}-\mathrm{C}_{6} \mathrm{H}_{4^{-}}$ & 4.925 & Prediction \\
\hline 4 & $4-\mathrm{Br}-\mathrm{C}_{6} \mathrm{H}_{4^{-}}$ & 4.907 & Training \\
\hline 5 & $4-\mathrm{O}_{2} \mathrm{~N}-\mathrm{C}_{6} \mathrm{H}_{4^{-}}$ & 4.778 & Training \\
\hline 6 & $4-\mathrm{HO}-\mathrm{C}_{6} \mathrm{H}_{4}-$ & 5.271 & Prediction \\
\hline 7 & 4-MeO- $\mathrm{C}_{6} \mathrm{H}_{4-}$ & 5.044 & Training \\
\hline 8 & $4-\mathrm{H}_{3} \mathrm{C}-\mathrm{C}_{6} \mathrm{H}_{4^{-}}$ & 5.070 & Training \\
\hline 9 & $3-\mathrm{F}-\mathrm{C}_{6} \mathrm{H}_{4}-$ & 4.803 & Training \\
\hline 10 & $3-\mathrm{F}_{3} \mathrm{C}-\mathrm{C}_{6} \mathrm{H}_{4}-$ & 5.286 & Training \\
\hline 11 & 3-MeO- $\mathrm{C}_{6} \mathrm{H}_{4}-$ & 5.123 & Training \\
\hline 12 & $2-\mathrm{F}-\mathrm{C}_{6} \mathrm{H}_{4}-$ & 4.837 & Training \\
\hline 13 & $2-\mathrm{O}_{2} \mathrm{~N}-\mathrm{C}_{6} \mathrm{H}_{4}-$ & 4.741 & Training \\
\hline 14 & $2-\mathrm{HO}-\mathrm{C}_{6} \mathrm{H}_{4}-$ & 5.401 & Training \\
\hline 15 & 2-HO-5-Cl- $\mathrm{C}_{6} \mathrm{H}_{3}-$ & 5.504 & Training \\
\hline 16 & 2-HO-5-Br- $\mathrm{C}_{6} \mathrm{H}_{3^{-}}$ & 5.369 & Training \\
\hline 17 & $2-\mathrm{HO}-3,5-2 \mathrm{Cl}^{-} \mathrm{C}_{6} \mathrm{H}_{3}-$ & 5.319 & Prediction \\
\hline 18 & $2-\mathrm{HO}-3,5-2 \mathrm{Br}-\mathrm{C}_{6} \mathrm{H}_{3}-$ & 5.148 & Training \\
\hline 19 & $3,4-2 \mathrm{HO}-\mathrm{C}_{6} \mathrm{H}_{3-}$ & 5.928 & Prediction \\
\hline 20 & 3-MeO-4-HO- $\mathrm{C}_{6} \mathrm{H}_{3}-$ & 5.539 & Training \\
\hline 21 & $2,4-2 \mathrm{Cl}-\mathrm{C}_{6} \mathrm{H}_{3}-$ & 4.749 & Prediction \\
\hline 22 & 2-Furan- & 5.016 & Training \\
\hline 23 & 2-Thiophene- & 4.871 & Training \\
\hline 24 & (E)-styryl- & 5.182 & Training \\
\hline
\end{tabular}

$71{ }^{\mathrm{a}}-\log \mathrm{IC}_{50}$; ${ }^{\mathrm{b}}$ the compounds considered for training and prediction set for QSAR study

72

73

74 


\subsection{Calculation of Descriptors}

A QSAR study requires the calculation of molecular descriptors. In order to have mechanistically interpretable descriptors, we limited the calculation to 1D-2D descriptors, since this study uses a ligand-based approach and 3D descriptors could instead be highly influenced by bound ligand conformations $(31,32)$. A total of $14441 \mathrm{D}$ and 2D molecular descriptors were calculated using PADEL 2.1 software (33). Constant and semi-constant values (>80\%), and correlated pairwise descriptors were excluded in a cleaning preliminary step (one of any two descriptors with a correlation greater than 0.95 was removed to reduce redundant information), and a final set of 195 molecular descriptors were used as input variables for model generation.

84

\subsection{Model generation}

Dataset was randomly split into a training set (19 compounds) for model generation, and a prediction set (5 compounds) for the validation of developed models, as reported in Table 1. First, the models were generated by the all-subset procedure with two variables, and subsequently by using genetic algorithm (GA) up to three variables, respecting the objects/descriptors ratio $\geq 5$ (27). We used the most common and transparent method, where models are described by clearly expressed mathematical equations: Multiple Linear Regression (MLR) by Ordinary Least Squares (OLS).

\subsection{Models validation}

The generated models were measured according to appropriate measures of goodness-of-fit, robustness, and predictive capability. Used statistics for goodness-of fit are: $\mathrm{R}^{2}>0.7$, concordance correlation coefficient (CCCtr) $>0.85$ (34), RMSE, $\mathrm{R}^{2}$ adj, and $\mathrm{R}^{2}-\mathrm{R}_{\text {adj. }}^{2}$ Used statistics to measure robustness of the model are: $\mathrm{Q}^{2}$ (eq.1) > 0.7, CCCcv, RMSEcv, $\mathrm{Q}^{2} \mathrm{LMO}$, and $\mathrm{R}^{2}$ calculated according $\mathrm{Y}$-scrambling procedure.

$$
\text { Eq.1 } \quad q^{2}=1-\frac{\sum_{i=1}^{\text {training }}\left(y_{i}-\widehat{y_{\iota}}\right)^{2}}{\sum_{i=1}^{\text {training }}\left(y_{i}-\bar{y}\right)^{2}}
$$

Where $\boldsymbol{y}_{\boldsymbol{i}} \widehat{\boldsymbol{y}}_{\boldsymbol{\imath}}$ are the actual and predicted activities of the ith molecule, respectively, and $\overline{\boldsymbol{y}}$ is the average activity of all molecules.

Predictive capability of the models generated was assessed by means of the external validation of the prediction set. Used statistics for external validation are: $\mathrm{Q}^{2}{ }_{\text {ext }}>0.70$ (eq.2), $\mathrm{Q}^{2}{ }_{\mathrm{F} 1}>0.70(35), \mathrm{Q}^{2} \mathrm{~F} 2>0.70(36), \mathrm{Q}^{2} \mathrm{~F} 3>0.70(37)$, Golbraikh and Tropsha parameters $k$ and $k^{\prime}(38), r^{2}$ metrics $>0.65$ (39), CCCext $>0.85(40)$

$$
\text { Eq.2 } \quad \boldsymbol{q}_{\text {ext }}^{2}=1-\frac{\sum_{i=1}^{t e s t}\left(y_{i}-\widehat{y_{t}}\right)^{2}}{\sum_{i=1}^{t e s t}\left(y_{i}-\overline{y_{t r}}\right)^{2}}
$$

Where $\boldsymbol{y}_{\boldsymbol{i}} \widehat{\boldsymbol{y}}_{\boldsymbol{\imath}}$ are the actual and predicted activities of the ith molecule, respectively, and $\overline{\boldsymbol{y}}_{\boldsymbol{t r}}$ is the average activity of all molecules in the training set.

With the aim to choose indeed the best performing model, excluding bias due to evaluating many statistic parameters at the same time, we decided to use the Multi-Criteria Decision Making (MCDM) (41). MCDM is an approach that sums up the performances of many criteria simultaneously. This is realized associating a desirability function, which values range from 0 to 1 (where 0 represents the worst validation criteria value and 1 the best), to every validation 
criterion. The MCDM scores reported in this paper are: MCDMfit regarding fitting criteria (maximizing $\mathrm{R}^{2}, \mathrm{R}^{2}{ }_{\text {adj, }}$ and CCCtr, and minimizing $\mathrm{R}^{2}-\mathrm{R}^{2}$ adj), MCDMcv regarding internal validation (maximizing $\mathrm{Q}^{2}, \mathrm{Q}^{2} \mathrm{LMO}$, CCCcv, and minimizing $\mathrm{R}^{2} \mathrm{yscr}$ ), MCDMext regarding external validation (maximizing $\mathrm{Q}^{2}{ }_{\mathrm{F} 1}, \mathrm{Q}^{2}{ }_{\mathrm{F} 2}, \mathrm{Q}^{2} \mathrm{~F}$, and CCCext). MCDMall, calculated with all the previous criteria, is able to determine the best compromise models among the selected validating criteria.

\subsection{Applicability Domain}

Prediction capability of modeled properties for the whole universe of chemicals is still not expected, even if robust and validated models are developed (42). QSAR models must be verified for their applicability domain, the latter having the ability to provide predicted data for compounds that are similar to chemicals used to generate the model. The applicability domain of the model was verified by the leverage approach, and fixed thresholds have been used to define both structural and response outliers. The Williams plot verified the presence of response outliers (compounds with cross-validated standardized residuals greater than 3.0 standard deviation units), and chemicals very structurally influent in determining model parameters. These latters are compounds with a leverage value (h) greater than $3 p^{\prime} / \mathrm{n}$ $\left(h^{*}\right)$ where $\mathrm{p}^{\prime}$ is the number of model variables plus one, and $\mathrm{n}$ is the number of the objects used to calculate the model.

\section{RESULTS AND DISCUSSION}

For the development of the QSAR models for 1,3,4-oxadiazole derivatives, MLR with OLS was applied. Initially, we generated models considering only one descriptor, then, we extended the calculation to two variables using the "allsubset” procedure, and finally, we proceeded to the third variable with GA. According to the fitness, robustness and predictive parameters, explained in materials and methods, some statistically significant models have been selected for discussion and mechanistic interpretation.

Model 1: $\mathrm{pIC}_{50}=+6.50( \pm 0.74)$ Intercept

7

$$
+0.12( \pm 0.04) \text { naaCH }
$$

$$
\begin{aligned}
& +25.5( \pm 3.54) \text { ETA_dEpsilon_D } \\
& -3.70( \pm 0.79) \text { ETA_BetaP_ns }
\end{aligned}
$$

$\mathrm{N}=19, \mathrm{R}^{2}=0.85, \mathrm{CCCtr}=0.92, \mathrm{RMSEtr}=0.09, \mathrm{R}^{2}$ adj $0.82, \mathrm{R}^{2}-\mathrm{R}^{2}{ }_{\text {adj }}=0.03$ fitness

$\mathrm{Q}^{2}=0.73, \mathrm{CCCcv}=0.86, \mathrm{RMSEcv}=0.12, \mathrm{Q}^{2} \mathrm{LMO}=0.71 \mathrm{R}^{2}{ }_{\text {yscr }}=0.16$ robustness

$\mathrm{Q}^{2}{ }_{\text {ext }}=0.95, \mathrm{Q}^{2}{ }_{\mathrm{F} 1}=0.93, \mathrm{Q}^{2}{ }_{\mathrm{F} 2}=0.92, \mathrm{Q}^{2}{ }_{\mathrm{F} 3}=0.78$, CCCext $=0.78, \mathrm{r}_{\mathrm{m}}^{2}=0.87, \mathrm{k}=1.01, \mathrm{k}^{\prime}=0.99$ predictive

42 In Figure 1 is shown the plot of experimental versus calculated endpoint.

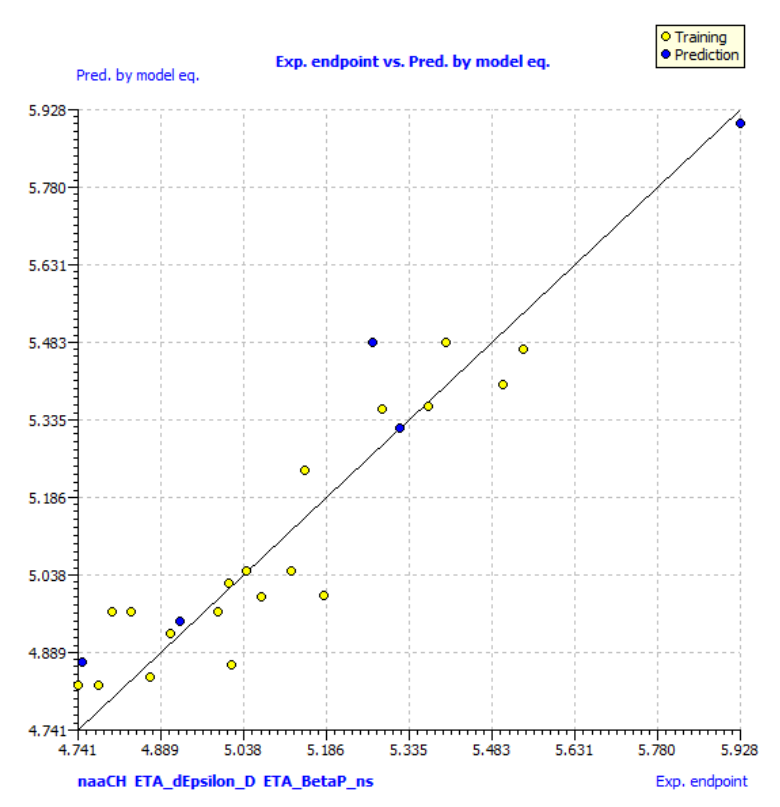


145

Model 1 is represented by a three parametric expression. This model, built using the GA-OLS method, has good measures of fitness above the optimal thresholds, and it shows an internal predictive power of $73 \%\left(Q^{2}=0.73\right)$ with a very low probability of random correlation among activity values and independent variables $\left(R_{y s c r}^{2}=0.16\right)$. The external predictive power on test set is good $\left(\mathrm{Q}^{2}{ }_{\text {ext }}=0.95\right)$, and all the other predictive parameters are above the considered significant thresholds. Descriptors are ordered according to their importance, based on their standardized coefficient values, which are reported in brackets after each descriptors symbol: ETA_dEpsilon_D $(+0.93)$ is a measure of contribution of hydrogen bond donor atoms; ETA_BetaP_ns (-0.47) is a measure of electron-richness of the molecule relative to molecular size; naaCH $(+0.37)$ is an electrotopological state index related to aromatic $\mathrm{CH}$ group.

In terms of applicability domain, one structural outlier has been identified (compound \#10) based on $\mathrm{h}^{*}=0.632$ (Figure 2).

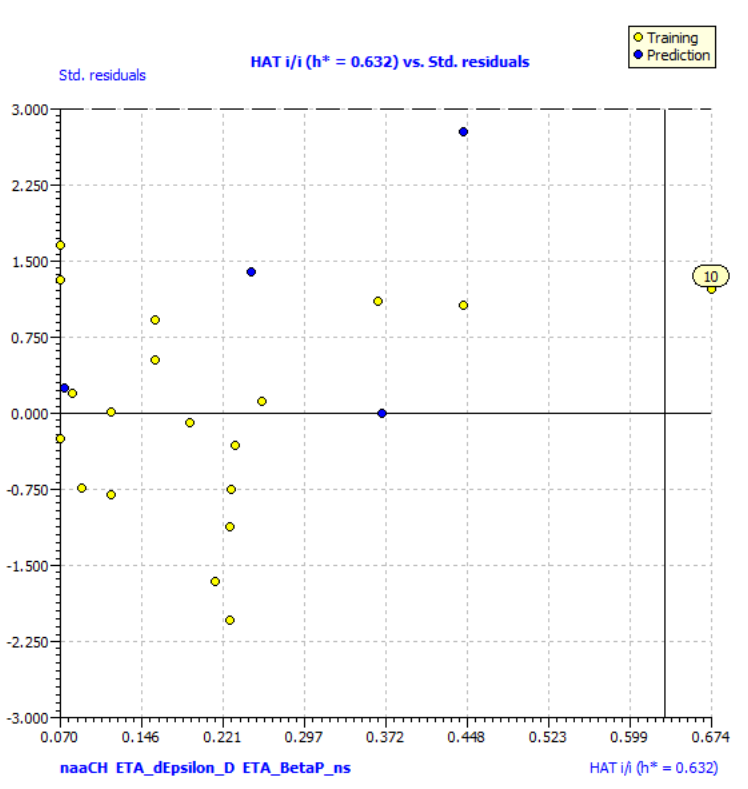

Figure 2. Applicability domain for model 1

Model 2: $\mathrm{pIC}_{50}=+7.67( \pm 0.74)$ Intercept

$$
-2.77( \pm 1.36) \mathrm{VCH}-7
$$$$
+22.49 \text { ( } \pm 3.46) \text { ETA_dEpsilon_D }
$$$$
\text { -3.55 ( } \pm 0.87) \text { ETA_BetaP_ns }
$$

$\mathrm{N}=19, \mathrm{R}^{2}=0.82, \mathrm{CCCtr}=0.90, \mathrm{RMSEtr}=0.10 \mathrm{R}_{\text {adj }}^{2}=0.78, \mathrm{R}^{2}-\mathrm{R}_{\text {adj }}{ }=0.04$ fitness

$\mathrm{Q}^{2}=0.72, \mathrm{CCCcv}=0.85, \mathrm{RMSEcv}=0.12, \mathrm{Q}^{2} \mathrm{LMO}=0.70 \mathrm{R}^{2}{ }_{\text {yscr }}=0.16$ robustness

$\mathrm{Q}^{2}{ }_{\mathrm{ext}}=0.96, \mathrm{Q}^{2} \mathrm{~F} 1=0.94, \mathrm{Q}^{2}{ }_{\mathrm{F} 2}=0.93, \mathrm{Q}^{2} \mathrm{~F}=0.80$, CCCext $=0.96, \mathrm{r}_{\mathrm{m}}^{2}=0.87, \mathrm{k}=1.01, \mathrm{k}=0.99$ predictivity 
In Figure 3 the plot of experimental versus calculated endpoint for model 2 is shown.

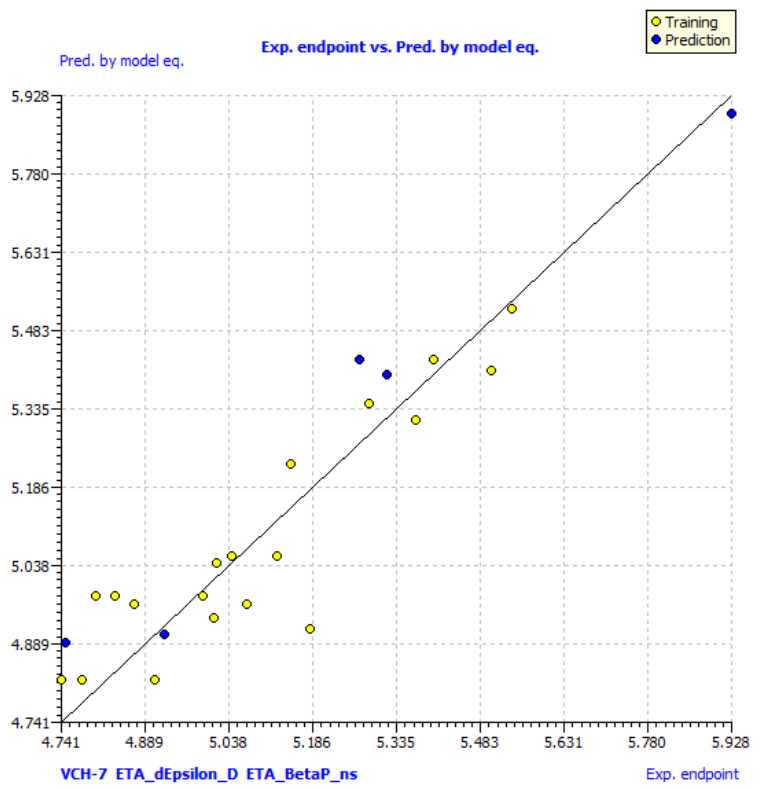

Figure 3 the plot of experimental versus calculated endpoint for model 2

Model 2 is also represented by a three parametric expression, and it was obtained using the same method of model 1. Model 2 has measures of fitness above the optimal thresholds too, and it shows an internal predictive power of $72 \%$ $\left(Q^{2}=0.72\right)$, with a very low probability of random correlation among activity values and independent variables $\left(\mathrm{R}^{2}{ }_{\text {yscr }}\right.$

$172=0.16)$. The external predictive power on test set is good $\left(\mathrm{Q}^{2}{ }_{\mathrm{ext}}=0.95\right)$, and all the other predictive parameters are 173 above the considered significant thresholds. Two of the descriptors correlated with the endpoint, are the same of model 174 1: ETA_dEpsilon_D (+0.81), and ETA_BetaP_ns (-0.45); the third descriptor is VCH-7 (-0.25), a topochemical 175 descriptor related to Kier-Hall indices (valence chain order 7), which is known for its importance in anticancer drug 176 design (43).

177 In terms of applicability domain, the same structural outlier of model 1 has been identified (compound \#10) based on $178 \mathrm{~h}^{*}=0.632$ (Figure 4).

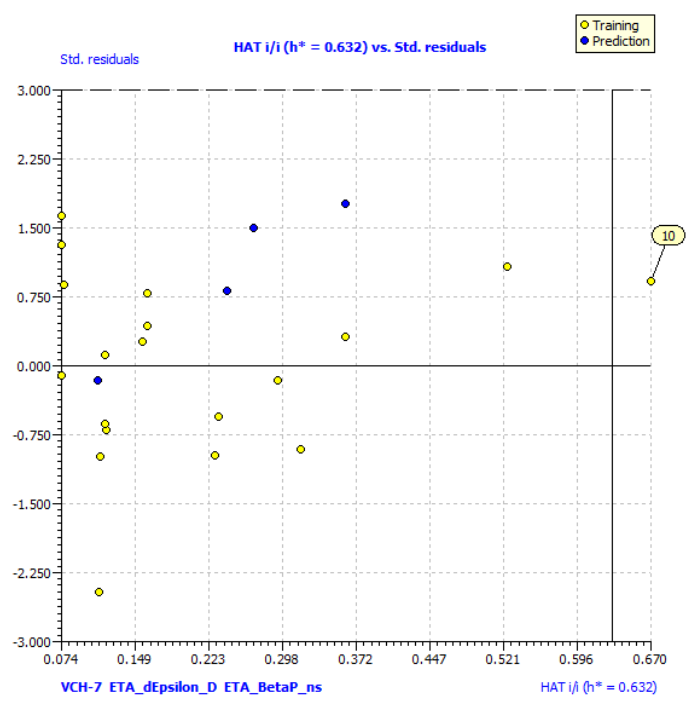


Figure 4. Applicability domain for model 2

Model 3: $\mathrm{pIC}_{50}=+5.96( \pm 1.17)$ Intercept

$$
\begin{aligned}
& +21.22( \pm 3.38) \text { ETA_dEpsilon_D } \\
& -4.81( \pm 1.21) \text { ETA_BetaP_ns } \\
& +8.68( \pm 5.10) \text { ETA_EtaP_F_L }
\end{aligned}
$$

$\mathrm{N}=19, \mathrm{R}^{2}=0.81, \mathrm{CCCtr}=0.89, \mathrm{RMSEtr}=0.10 \mathrm{R}^{2}{ }_{\mathrm{adj}}=0.77, \mathrm{R}^{2}-\mathrm{R}^{2}{ }_{\mathrm{adj}}=0.04$ fitness

$\mathrm{Q}^{2}=0.70, \mathrm{CCCcv}=0.89, \mathrm{RMSEcv}=0.13, \mathrm{Q}^{2} \mathrm{LMO}=0.68 \mathrm{R}^{2}{ }_{\text {yscr }}=0.17$ robustness

$\mathrm{Q}^{2}{ }_{\text {ext }}=0.96, \mathrm{Q}^{2} \mathrm{F1}=0.92, \mathrm{Q}^{2} \mathrm{F2}=0.91, \mathrm{Q}^{2} \mathrm{F3}=0.75$, CCCext $=0.95, \mathrm{r}_{\mathrm{m}}^{2}=0.80, \mathrm{k}=1.01, \mathrm{k}^{\prime}=0.99$ predictivity

As the previous models, Model 3 is also represented by a three parametric expression and has measures of fitness above the optimal thresholds. In fact it shows an internal predictive power of $70 \%\left(Q^{2}=0.70\right)$, with a very low probability of random correlation among activity values and independent variables $\left(R^{2}\right.$ yscr $\left.=0.17\right)$. The external predictive power on test set is good $\left(\mathrm{Q}^{2}\right.$ ext $\left.=0.96\right)$, and all the other predictive parameters are above the considered significant thresholds. This model comprises two previously retrieved descriptors too: ETA_dEpsilon_D (+0.77), and ETA_BetaP_ns (-0.61); the third descriptor is ETA_EtaP_F_L, another extended topochemical atom descriptor, which correlates local functionality contribution (EtaF_local) with molecular size. The local functionality index was proposed to measure the molecule functionality, intended as the presence of heteroatoms and multiple bonds (44). In Figure 5 the plot of experimental versus calculated endpoint for Model 3

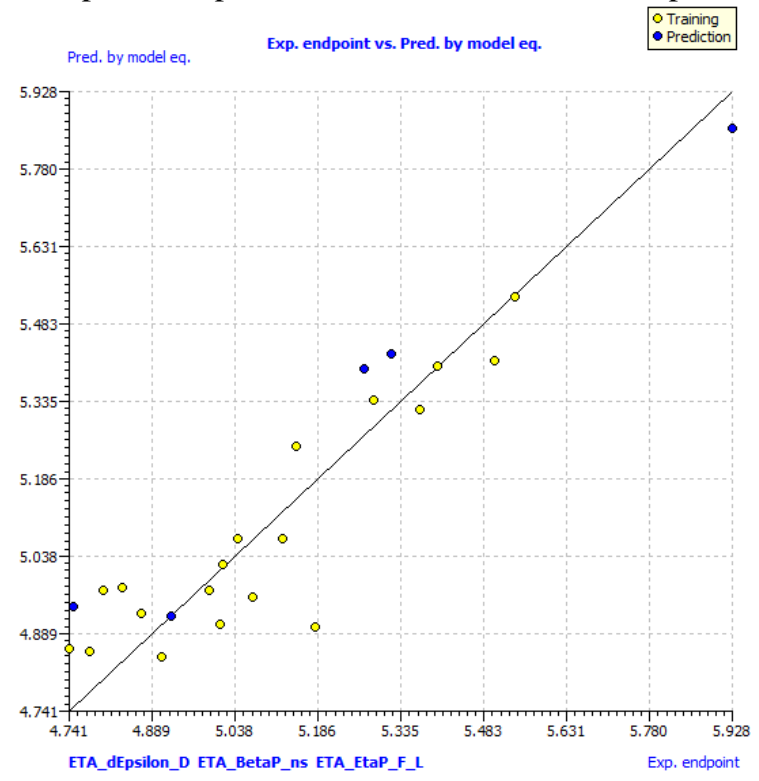

Figure 5 plot of experimental versus calculated endpoint for Model 3

In terms of applicability domain, Model 3 is quite similar to the previous two, with only compound \#10 as structural outlier (Figure 6). 


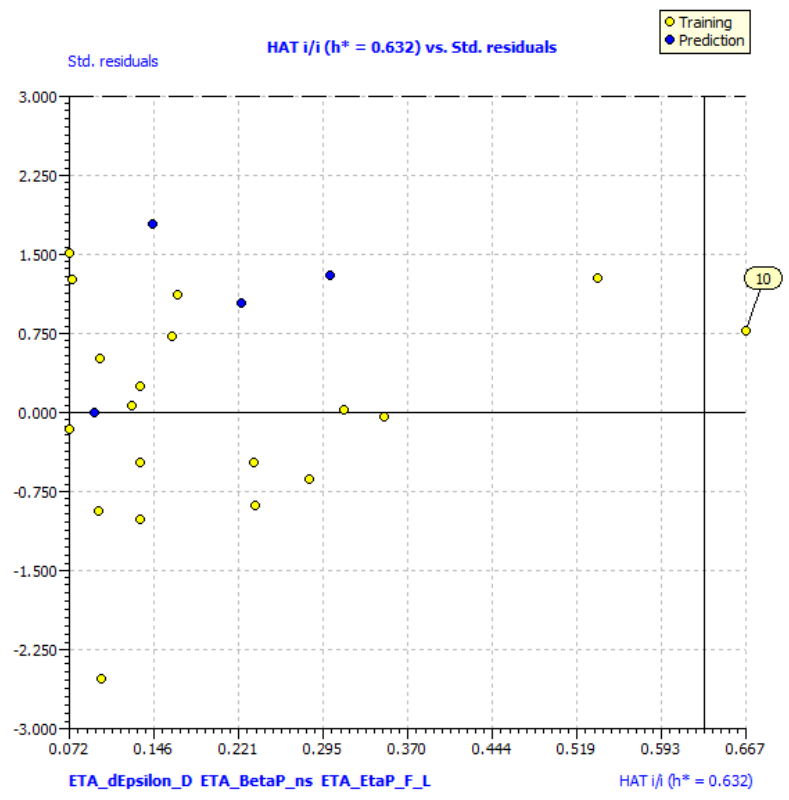

Figure 6. Applicability domain for model 3

204 All the three models identified showed good parameters of fitness, robustness and predictive capability. They differ 205 from each other by a single descriptor, and in terms of applicability domain have a quite similar behavior. Therefore, in such a landscape of QSAR models, the choice of the best performing model to identify new and more potent compounds could be very difficult. For this reason, we decided to entrust the management of the best performing model to the MCDM criteria. In Table 2, predicted and residuals for the three QSAR models are reported. In Table 3, the MCDM values are shown. Model 1 could have, in terms of MCDMall, the best performing capability, even though with a slight difference compared to the other two models. As the last choice criteria, we decided to consider the significance (p-value) of descriptors coefficients in each model. In Model 1, all the descriptor coefficients have pvalue $<0.05$; in model 2, VCH-7 has p-value $>0.05$, such as in model 3, ETA_EtaP_F_L has p-value $>0.10$. When pvalue for descriptors coefficients are under the confidence threshold of $95 \%$, models should be considered with caution. In the light of this latter considerations, Model 1, in virtue of the best MCDMall value, and in virtue of p- 
Table 2. predicted and residuals for the three QSAR models

\begin{tabular}{|c|c|c|c|c|c|c|c|c|}
\hline & STATUS & $E X P$. & $M C$ & EL 1 & $M C$ & EL 2 & & 219 \\
\hline & & & Pred. & Res. & Pred. & Res. & Pred. & Res. \\
\hline 1 & Training & 5.012 & 5.023 & 0.011 & 4.939 & -0.073 & 4.910 & -0.102 \\
\hline 2 & Training & 4.992 & 4.968 & -0.024 & 4.981 & -0.011 & 4.974 & -0.018 \\
\hline 3 & Prediction & 4.925 & 4.951 & 0.026 & 4.908 & -0.017 & 4.925 & 0.090 \\
\hline 4 & Training & 4.907 & 4.927 & 0.020 & 4.823 & -0.084 & 4.845 & -0.062 \\
\hline 5 & Training & 4.778 & 4.828 & 0.050 & 4.824 & 0.046 & 4.856 & 0.9738 \\
\hline 6 & Prediction & 5.271 & 5.483 & 0.212 & 5.431 & 0.160 & 5.399 & 0.128 \\
\hline 7 & Training & 5.044 & 5.046 & 0.002 & 5.057 & 0.013 & 5.072 & 2.2348 \\
\hline 8 & Training & 5.070 & 4.998 & -0.072 & 4.966 & -0.104 & 4.960 & -0.110 \\
\hline 9 & Training & 4.803 & 4.968 & 0.165 & 4.981 & 0.178 & 4.974 & 6.471 \\
\hline 10 & Training & 5.286 & 5.358 & 0.072 & 5.346 & 0.060 & 5.339 & 0.053 \\
\hline 11 & Training & 5.123 & 5.046 & -0.077 & 5.057 & -0.066 & 5.072 & -0.051 \\
\hline 12 & Training & 4.837 & 4.968 & 0.131 & 4.981 & 0.144 & 4.980 & 0.143 \\
\hline 13 & Training & 4.741 & 4.828 & 0.087 & 4.824 & 0.083 & 4.861 & 0.120 \\
\hline 14 & Training & 5.401 & 5.483 & 0.082 & 5.431 & 0.030 & 5.404 & 0.003 \\
\hline 15 & Training & 5.504 & 5.404 & -0.100 & 5.408 & -0.096 & 5.414 & -8.990 \\
\hline 16 & Training & 5.369 & 5.361 & -0.008 & 5.315 & -0.054 & 5.321 & -0.048 \\
\hline 17 & Prediction & 5.319 & 5.319 & 0.000 & 5.400 & 0.081 & 5.427 & 2.308 \\
\hline 18 & Training & 5.148 & 5.239 & 0.091 & 5.233 & 0.085 & 5.250 & 0.102 \\
\hline 19 & Prediction & 5.928 & 5.904 & -0.024 & 5.895 & -0.033 & 5.859 & -8.3199 \\
\hline 20 & Training & 5.539 & 5.472 & -0.067 & 5.525 & -0.014 & 5.536 & -0.004 \\
\hline 21 & Prediction & 4.749 & 4.873 & 0.124 & 4.894 & 0.145 & 4.943 & 6.194 \\
\hline 22 & Training & 5.016 & 4.866 & -0.150 & 5.044 & 0.028 & 5.023 & 0.007 \\
\hline 23 & Training & 4.871 & 4.843 & -0.028 & 4.967 & 0.096 & 4.929 & 0.058 \\
\hline 24 & Training & 5.182 & 4.999 & -0.183 & 4.921 & -0.262 & 4.903 & -0.280 \\
\hline
\end{tabular}

Table 3. MCDM values for the QSAR models

\begin{tabular}{|c|c|c|c|c|}
\hline & & $M C D M C V$ & $\begin{array}{l}\text { MCDM } \\
\text { EXT }\end{array}$ & $\begin{array}{l}239 \\
M C D M \\
A L L\end{array}$ \\
\hline MODEL 1 & 0.871 & 0.753 & 0.888 & 0.835 \\
\hline MODEL 2 & 0.843 & 0.742 & 0.901 & 9) 46 \\
\hline MODEL 3 & 0.831 & 0.726 & 0.871 & 0.807 \\
\hline
\end{tabular}




\section{CONCLUSION}

In this paper, we have successfully developed robust and predictive QSAR models for 1,3,4-oxadiazole derivatives as telomerase inhibitors. The results obtained in this study suggests that QSAR models developed with 1D and 2D molecular descriptors can be used for the design of new analogs with more potent telomerase inhibitory activity as anticancer drugs. In particular, Model 1 revealed to be the most reliable. A posteriori mechanistic interpretation of descriptors included in the model suggests important structural information. The ETA (Extended topochemical atom) descriptor ETA_dEpsD, which takes into account the contribute of H-donor atoms, increases according to the presence of donor atoms into the aromatic ring. At the same time, the Electrotopological-state descriptor naaCH, which considers the aromatic $\mathrm{CH}$, has a positive coefficient: this suggests that too many substitutions on the aromatic ring could lead to non-active compounds. The last descriptors, the ETA descriptor ETA_dEpsD, which takes into account the electron-richness of the molecule relative to molecular size, slightly decreases related to the endpoint, so this suggests that electron-rich substituents do not have to be in excessive number related to dimension of the compounds. Therefore, we hope that this theoretical approach, and obtained structural information, could be an important aid in the design of novel compounds, to boost the identification of lead compounds to be tested in vitro and in vivo.

\section{LIST OF ABBREVIATIONS}

OECD, Organisation for Economic Co-operation and Development; QSAR, Quantitative Structure-Activity Relationships; MLR, Multi Linear Regression; OLS, Ordinary Least Squares; MCDM, Multi Criteria Decision Making; TER, template-encoding RNA; TERT, telomerase reverse transcriptase; TRBD, telomerase RNA binding domain, E-state, Electro topological state; ETA, Extended topochemical atom.

\section{CONFLICT OF INTEREST}

The authors confirm the article content has not conflict of interest.

\section{ACKNOWLEDGEMENTS}

All listed as authors must have contributed equally to the design, performance, and analysis of the work.

Special thanks to Prof. Paola Gramatica and colleagues who licensed the free use of their software QSARINS v.2.21(45) used for the creation and validation of the models of this manuscript.

\section{REFERENCES}

1. Wright WE, Shay JW. Telomere dynamics in cancer progression and prevention: fundamental differences in human and mouse telomere biology. Nat Med [Internet]. 2000;6(8):849-51. Available from: http://www.ncbi.nlm.nih.gov/pubmed/10932210

2. Karlseder J, Smogorzewska A, de Lange T, Bodnar AG, Harley CB, Futcher AB, et al. Senescence induced by altered telomere state, not telomere loss. Science [Internet]. 2002;295(5564):2446-9. Available from: http://www.ncbi.nlm.nih.gov/pubmed/11923537

3. Bodnar AG, Ouellette M, Frolkis M, Holt SE, Chiu CP, Morin GB, et al. Extension of life-span by introduction of telomerase into normal human cells. Science [Internet]. 1998;279(5349):349-52. Available from: http://www.ncbi.nlm.nih.gov/pubmed/9454332

4. Gillis AJ, Schuller AP, Skordalakes E. Structure of the Tribolium castaneum telomerase catalytic subunit TERT. Nature. 2008;455(7213):633-7.

5. Shay JW, Bacchetti S. A survey of telomerase activity in human cancer. Eur J Cancer [Internet]. 1997;33(5):787-91. Available from: http://www.sciencedirect.com/science/article/pii/S0959804997000622

6. Broccoli D, Young JW, de Lange T. Telomerase activity in normal and malignant hematopoietic cells. Proc Natl Acad Sci U S A. 1995;92(20):9082-6.

7. Kim NW, Piatyszek MA, Prowse KR, Harley CB, West MD, Ho PL, et al. Specific association of human telomerase activity with immortal cells and cancer. Science [Internet]. 1994;266(5193):2011-5. Available from: http://www.ncbi.nlm.nih.gov/pubmed/7605428 
Steczkiewicz K, Zimmermann MT, Kurcinski M, Lewis B a, Dobbs D, Kloczkowski A, et al. Human telomerase model shows the role of the TEN domain in advancing the double helix for the next polymerization step. Proc Natl Acad Sci U S A. 2011;108(23):9443-8.

9. Autexier C, Lue NF. The structure and function of telomerase reverse transcriptase. Annu Rev Biochem. 2006;75:493-517.

10. Herbert B, Pitts AE, Baker SI, Hamilton SE, Wright WE, Shay JW, et al. Inhibition of human telomerase in immortal human cells leads to progressive telomere shortening and cell death. Proc Natl Acad Sci U S A. 1999;96(25):14276-81.

11. Sun D, Thompson B, Cathers BE, Salazar M, Kerwin SM, Trent JO, et al. Inhibition of human telomerase by a G-QuadruplexInteractive compound. Vol. 40, Journal of Medicinal Chemistry. 1997. p. 2113-6.

12. Strahl C, Blackburn EH. Effects of reverse transcriptase inhibitors on telomere length and telomerase activity in two immortalized human cell lines. Mol Cell Biol. 1996;16(1):53-65.

13. Lauria A, Terenzi A, Bartolotta R, Bonsignore R, Perricone U, Tutone M, et al. Does ligand symmetry play a role in the stabilization of DNA g-quadruplex host-guest complexes? Curr Med Chem [Internet]. 2014;21(23):2665-90. Available from: http://www.ncbi.nlm.nih.gov/pubmed/24533802

14. Paul A, Maji B, Misra SK, Jain AK, Muniyappa K, Bhattacharya S. Stabilization and structural alteration of the G-quadruplex DNA made from the human telomeric repeat mediated by Tröger's base based novel benzimidazole derivatives. J Med Chem. 2012;55(17):7460-71.

15. El-sayed W a, El-essawy F a, Ali OM, Nasr BS. Anti-HIV Activity of New Substituted 1, 3 , 4-Oxadiazole Derivatives and their Acyclic Nucleoside Analogues. 2009;11.

16. Abadi AH, Eissa AAH, Hassan GS. Synthesis of novel 1,3,4-trisubstituted pyrazole derivatives and their evaluation as antitumor and antiangiogenic agents. Chem Pharm Bull (Tokyo) [Internet]. 2003;51(7):838-44. Available from: http://www.ncbi.nlm.nih.gov/pubmed/22741785

17. Szczepankiewicz BG bruce g, Chiou WJ, Credo RB, Alder JD, Nukkala MA, Zielinski NA, et al. New antimitotic agents with activity in multi-drug-resistant cell lines and in vivo efficacy in murine tumor models. J Med Chem. 2001;44(25):4416-30.

18. Zheng QZ, Zhang XM, Xu Y, Cheng K, Jiao QC, Zhu HL. Synthesis, biological evaluation, and molecular docking studies of 2chloropyridine derivatives possessing 1,3,4-oxadiazole moiety as potential antitumor agents. Bioorganic Med Chem [Internet]. Elsevier Ltd; 2010;18(22):7836-41. Available from: http://dx.doi.org/10.1016/j.bmc.2010.09.051

19. Zhang XM, Qiu M, Sun J, Zhang Y Bin, Yang YS, Wang XL, et al. Synthesis, biological evaluation, and molecular docking studies of 1,3,4-oxadiazole derivatives possessing 1,4-benzodioxan moiety as potential anticancer agents. Bioorganic Med Chem [Internet]. Elsevier Ltd; 2011;19(21):6518-24. Available from: http://dx.doi.org/10.1016/j.bmc.2011.08.013

20. Linder J, Garner TP, Williams HEL, Searle MS, Moody CJ. Telomestatin: Formal total synthesis and cation-mediated interaction of its seco-derivatives with G-quadruplexes. J Am Chem Soc. 2011;133(4):1044-51.

21. Wang Y, Cheng FX, Yuan XL, Tang WJ, Shi JB, Liao CZ, et al. Dihydropyrazole derivatives as telomerase inhibitors: Structure-based design, synthesis, SAR and anticancer evaluation in vitro and in vivo. Eur J Med Chem [Internet]. Elsevier Masson SAS; 2016;112:231-51. Available from: http://dx.doi.org/10.1016/j.ejmech.2016.02.009

Xiao X, Ni Y, Jia YM, Zheng M, Xu HF, Xu J, et al. Identification of human telomerase inhibitors having the core of N-acyl-4,5dihydropyrazole with anticancer effects. Bioorganic Med Chem Lett [Internet]. Elsevier Ltd; 2016;26(6):1508-11. Available from: http://dx.doi.org/10.1016/j.bmcl.2016.02.025

23. Zhang H-J, Qian Y, Zhu D-D, Yang X-G, Zhu H-L. Synthesis, molecular modeling and biological evaluation of chalcone thiosemicarbazide derivatives as novel anticancer agents. Eur J Med Chem [Internet]. Elsevier Masson SAS; 2011;46(9):4702-8. Available from: http://www.ncbi.nlm.nih.gov/pubmed/23279864\%5Cnhttp://linkinghub.elsevier.com/retrieve/pii/S0223523412007167\%5Cnhttp://linki nghub.elsevier.com/retrieve/pii/S0223523411005290

Kubinyi H. QSAR and 3D QSAR in drug design part 2: Applications and problems. Drug Discov Today. 1997;2(12):538-46.

Almerico A, Tutone M, Ippolito M, Lauria A. Molecular Modelling and QSAR in the Discovery of HIV-1 Integrase Inhibitors. Curr Comput Aided-Drug Des. 2007 Sep;3(3):214-33.

Almerico AM, Tutone M, Lauria A. Issue in Honor of Prof Nicolò Vivona A QSAR study investigating the potential anti-HIV-1 effect of some Acyclovir and Ganciclovir analogs.

Gramatica P. Principles of QSAR models validation: Internal and external. QSAR Comb Sci. 2007;26(5):694-701.

Pibiri I, Lentini L, Tutone M, Melfi R, Pace A, Di Leonardo A. Exploring the readthrough of nonsense mutations by non-acidic Ataluren analogues selected by ligand-based virtual screening. Eur J Med Chem. 2016;122:429-35.

Boström J, Hogner A, Llinàs A, Wellner E, Plowright AT. Oxadiazoles in medicinal chemistry. J Med Chem. 2012;55(5):1817-30. 
benzylidene-2-((5-(pyridin-4-yl)-1,3,4-oxadiazol-2-yl)thio)acetohydrazide derivatives as potential anticancer agents. Bioorg Med Chem [Internet]. Elsevier Ltd; 2014;22(1):468-77. Available from: http://www.ncbi.nlm.nih.gov/pubmed/24286761

31. descriptors. Eur J Med Chem. 2011;46(9):4274-80.

Tutone M, Perricone U, Almerico AM. Conf-VLKA: A structure-based revisitation of the Virtual Lock-and-Key Approach. J Mol Graph Model [Internet]. Elsevier Inc.; 2016;71:50-7. Available from: http://linkinghub.elsevier.com/retrieve/pii/S1093326316303801

33. Yap CW. PaDEL-descriptor: An open source software to calculate molecular descriptors and fingerprints. J Comput Chem. 2011;32(7):1466-74.

34. Chirico N, Gramatica P. Real external predictivity of QSAR models. Part 2. New intercomparable thresholds for different validation criteria and the need for scatter plot inspection. J Chem Inf Model. 2012;52(8):2044-58.

35. Shi LM, Fang H, Tong W, Wu J, Perkins R, Blair RM, et al. QSAR models using a large diverse set of estrogens. J Chem Inf Comput Sci [Internet]. 2001;41(1):186-95. Available from: http://www.ncbi.nlm.nih.gov/pubmed/11206373

36. Schüürmann G, Ebert RU, Chen J, Wang B, Kühne R. External validation and prediction employing the predictive squared correlation coefficient - Test set activity mean vs training set activity mean. J Chem Inf Model. 2008;48(11):2140-5.

37. Consonni V, Ballabio D, Todeschini R. Comments on the Definition of the Q2Parameter for QSAR Validation. J Chem Inf Model [Internet]. 2009;49(7):1669-78. Available from: http://pubs.acs.org/doi/abs/10.1021/ci900115y\%5Cnpapers3://publication/doi/10.1021/ci900115y

38. Golbraikh A, Tropsha A. Beware of q²! J Mol Graph Model [Internet]. 2002;20(4):269-76. Available from: http://www.ncbi.nlm.nih.gov/pubmed/11858635

39. Ojha PK, Mitra I, Das RN, Roy K. Further exploring rm2 metrics for validation of QSPR models. Chemom Intell Lab Syst [Internet]. Elsevier B.V.; 2011;107(1):194-205. Available from: http://dx.doi.org/10.1016/j.chemolab.2011.03.011

40. Lin LI. A Concordance Correlation Coefficient to Evaluate Reproducibility Author ( s ): Lawrence I-Kuei Lin Published by : International Biometric Society Stable URL : http://www.jstor.org/stable/2532051 REFERENCES Linked references are available on JSTOR for thi. 2016;45(1):255-68.

41. Keller HR, Massart DL, Brans JP. Multicriteria decision making: A case study. Chemom Intell Lab Syst [Internet]. $1991 ; 11(2): 175-89$. Available from: http://www.sciencedirect.com/science/article/pii/016974399180064W

42. Bhhatarai B, Teetz W, Liu T, Öberg T, Jeliazkova N, Kochev N, et al. CADASTER QSPR Models for predictions of melting and boiling points of perfluorinated chemicals. Mol Inform. 2011;30(2-3):189-204.

43. Nandi S, Bagchi MC. Importance of Kier-Hall topological indices in the QSAR of anticancer drug design. Curr Comput Aided Drug Des [Internet]. 2012;8(2):159-70. Available from: http://www.ncbi.nlm.nih.gov/pubmed/22497470

44. Todeschini R, Consonni V. Molecular Descriptors for Chemoinformatics [Internet]. Recent Advances in QSAR Studies. 2010. 29-103 p. Available from: http://www.wiley-vch.de/publish/en/books/specialOffer/3-527-318526/?sID=6de4ec6262b15323b6e71478c175dabe QSAR MLR models. J Comput Chem. 2013;34(24):2121-32. 